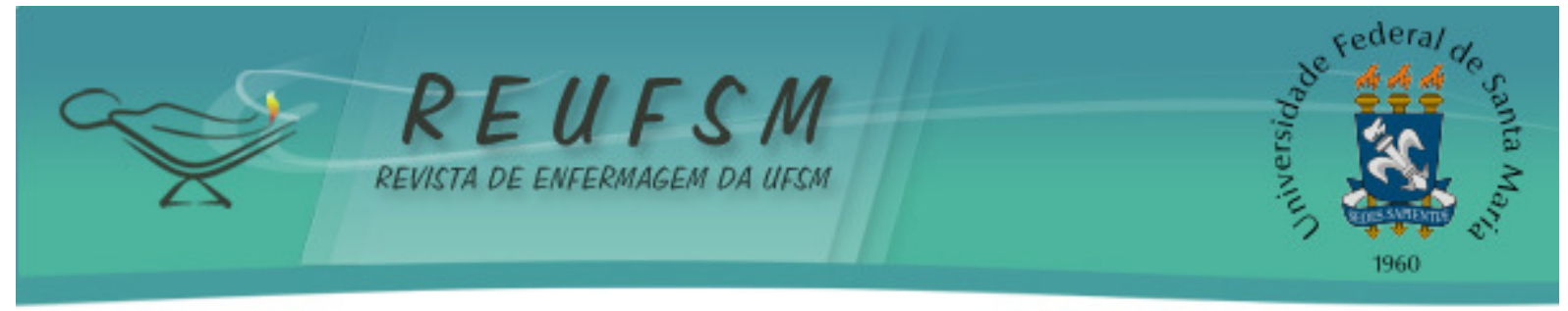

EDITORIAL

\title{
EM PAUTA A INTERNACIONALIZAÇÃO E VISIBILIDADE DA COMUNICAÇÃO CIENTÍFICA DE ENFERMAGEM
}

\section{IN EVIDENCE: INTERNATIONALIZATION AND VISIBILITY OF CIENTIFIC COMMUNICATION IN NURSING}

\author{
EN DISCUSIÓN LA INTERNACIONALIZACIÓN Y VISIBILIDAD DE LA COMUNICACIÓN \\ CIENTÍFICA DE LA ENFERMERÍA
}

Maria da Graça Oliveira Crossetti ${ }^{1}$

A natureza internacional da ciência é inquestionável. Fato que exige dos atores que a fazem acontecer um compromisso autêntico na difusão do conhecimento que produzem. Condição que tem exigido de diferentes disciplinas pensar e desenvolver estudos cujos resultados possibilitem o diálogo com a comunidade cientifica internacional perante o exercício da crítica e ou apropriação do conhecimento produzido.

A globalização com seus aspectos negativos e ou positivos tem imposto esta conduta aos pesquisadores, respeitado as crenças e cultura de cada realidade, ou seja, sua singularidade, contudo com esforços plurais e sinérgicos dado as similaridades das vivências e experiências situacionais.

A internacionalização e globalização, no contexto atual, na comunicação científica devem ser assumidas como um $\mathrm{fim}^{1}$, pois caracterizam-se pelas necessidades de relacionamento entre as nações no cumprimento de agendas governamentais prioritárias referentes a estratégias para a solução conjunta dos mais distintos problemas que afetam a sociedade mundial.

Motivo pelo qual nos últimos anos, vem acontecendo o que denomina-se de movimento a internacionalização e visibilidade da produção científica brasileira, meio pelo qual promove o consumo das pesquisas bem como dá visibilidade e credibilidade ao pesquisador. Isto porque, constata-se a influência dos periódicos nacionais na cientometria internacional de forma positiva na quantidade de artigos, contudo negativa nas citações recebidas por artigos ${ }^{2}$, embora seja notório o crescimento expressivo de novos periódicos nas mais diferentes áreas do conhecimento.

Nesta perspectiva desvela-se a comunicação científica da enfermagem brasileira, que nos últimos anos tem assumido lugar nunca dantes alcançado, pois o Brasil encontra-se em primeiro lugar neste cenário na Região das Américas. Fato que se justifica pelo crescimento dos programas pós-graduação, mestrado e doutorado, dos egressos e, consequentemente, da qualidade das produções de pesquisas ${ }^{3}$ desenvolvidas nas mais diferentes abordagens e contextos da prática profissional.

É evidente o crescente número da comunicação cientifica dos enfermeiros brasileiros divulgada em revistas de alto impacto, indexadas em bases de dados internacionais como Scopus/SCImago, Medline, CINAHL - Cumulative Index to Nursing \& Allied Health Literature, CUIDEN, SciELO - Scientific Eletronic Library Online, LILACS Literatura Latino Americana e do Caribe em Ciências da Saúde e Rev@Enf da Biblioteca Virtual de Saúde Enfermagem - BVS/Enf. Contudo esta produção é resultante de pesquisas desenvolvidas a nível nacional. Fato muito importante, mas relevante para o contexto em

\footnotetext{
1 Professor Titular do Departamento de Enfermagem Médico Cirúrgica da Escola de Enfermagem da Universidade Federal do Rio Grande do Sul (UFRGS). Professor do Programa de Pós-Graduação da Escola de Enfermagem da UFRGS. Coordenadora do Núcleo de Estudo do Cuidado na Enfermagem da Escola de Enfermagem da UFRGS. Editor Chefe da Revista Gaúcha de Enfermagem da Escola de Enfermagem da UFRGS
} 


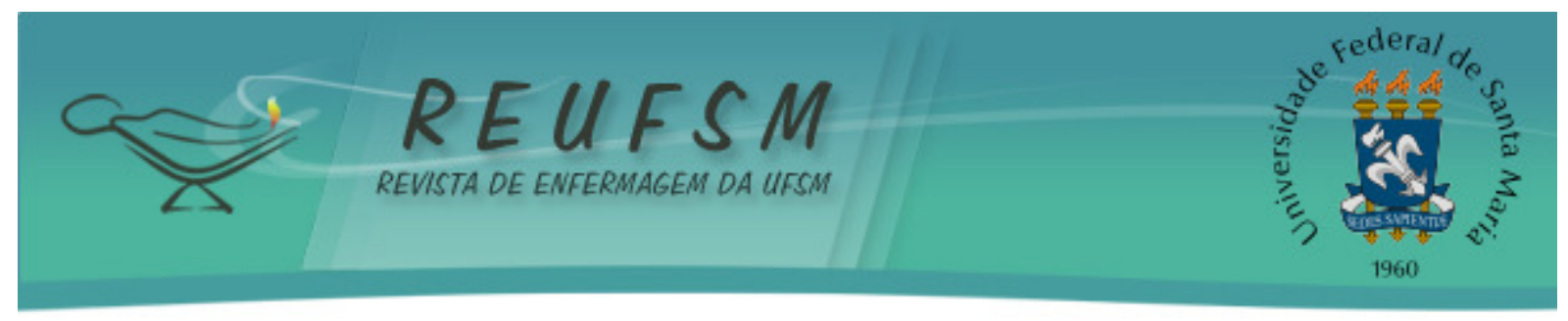

que foi desenvolvida. Portanto se a internacionalização e a visibilidade da comunicação cientifica em enfermagem é a meta, faz-se necessário que os objetos destes estudos assim como seus resultados tenham impacto nos processos saúde-doença das populações de outros países no cenário mundial.

Pauta que com outros assuntos semelhantes foi discutida na Conferência Internacional de Comunicação Científica e Difusão do Conhecimento em Enfermagem, nos dias 10 e 11 de setembro próximo passado em Belo Horizonte-MG. Nesta estiveram presentes representantes de 20 países da Região das Américas e de Portugal representados nas pessoas dos editores de periódicos de enfermagem e representantes de instituições internacionais cooperantes no processo de comunicação científica em Enfermagem. 0 evento teve como objetivo incentivar estes atores a desenvolver um plano de trabalho conjunto que estabeleça princípios, diretrizes, prioridades, matriz de responsabilidades e processos inovadores no desenvolvimento da comunicação científica por meio da BVS Enfermagem nos países da Região das Américas.

$\mathrm{Na}$ Conferência ficou evidente nas diferentes seções programadas que é significativa a produção científica de enfermagem nas últimas décadas nesta realidade. Mas, embora a quantidade e qualidade metodológica, são produções nucleares desenvolvidas e consumidas apenas no sítio local, regional ou nacional e divulgadas em periódicos próprios e ou de outras áreas do conhecimento do país sede das pesquisas. Neste contexto, a lacuna de estudos multicêntricos foi uma necessidade sentida.

Concluiu-se ainda, neste evento, que o impacto da crítica e ou apropriação destes estudos no cenário internacional é frágil, somado ao fato de que são produções em sua maioria no idioma espanhol, retratando o inglês apenas no resumo. Poucos são os periódicos de enfermagem que publicam além da língua materna, ou seja, a versão do artigo na íntegra no idioma inglês. Questiona-se, pois como internacionalizar e dar visibilidade a esta produção científica em outros cenários da enfermagem como nos norte americano e anglo saxônico?

A difusão da comunicação científica na enfermagem têm nos últimos anos sido objeto de discussão nos mais diferentes fóruns da área e naqueles que a afetam, no sentido de promover estratégias para aumentar a visibilidade e consequente internacionalização dos seus periódicos. São estes por excelência os veículos pelos quais os consumidores, na figura dos pesquisadores e outros indivíduos, tomam ciência do estado da arte do então produzido.

A indexação em bases de dados nacionais e internacionais que detém criticidade científica para a indexação confere ao periódico credibilidade e reconhecimento o que é extensivo aos autores e artigos que publica; indicadores de qualidade relevantes para o pesquisador ao selecionar a melhor revista para a divulgação dos seus estudos.

O Brasil tem procurado divulgar a pesquisa brasileira aumentando a colaboração internacional, isto é incipiente em algumas áreas do conhecimento como a enfermagem. Por isso faz-se necessário a adoção de critérios pelos periódicos nacionais, ampliando seu escopo e adequando sua linha editorial, promovendo a competitividade com os periódicos produzidos em outras realidades.

Em sua $4^{a}$ Reunião Anual em dezembro de 2014 em São Paulo - Brasil, a SciELO (Scientific Electronic Library Online) anunciou medidas para a internacionalização dos periódicos científicos brasileiros considerando que a ciência é, por natureza, internacional. $^{2}$

Entre as medidas propostas para a área da saúde, onde se insere a enfermagem, destacam-se os seguintes critérios que os periódicos deverão atender a partir de janeiro de 2016: 


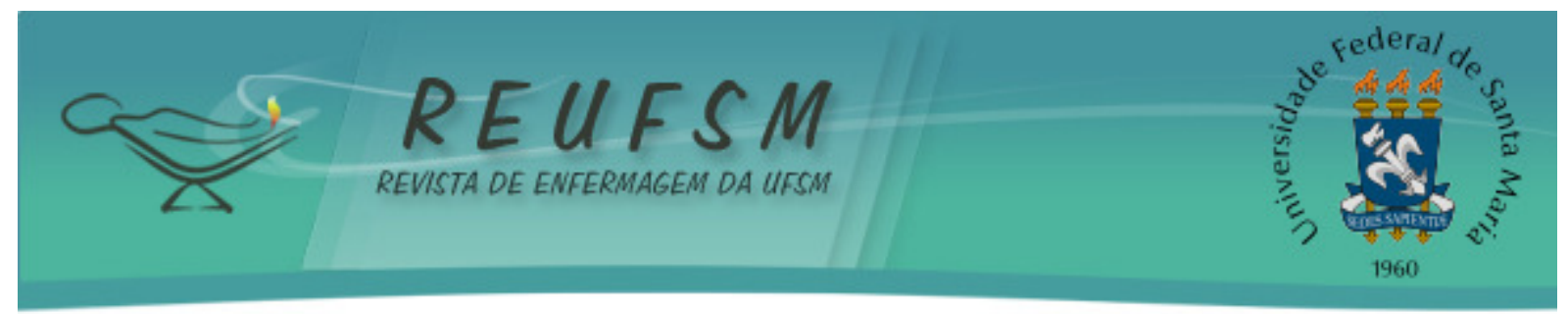

- maximizar a internacionalização do corpo de editores associados e de pareceristas, possuindo, respectivamente, um mínimo de $20 \%$ e $25 \%$ com afiliação estrangeira;

- publicar artigos de autores com afiliação estrangeira (mínimo de 25\%);

- adotar sistema de avaliação peer review;

- registrar avaliações dos pareceristas;

- publicar simultaneamente nos idiomas português e inglês;

- adotar sistema para controle de plágio;

- contar com o apoio de um sistema de gestão online;

- minimizar o tempo entre submissão e publicação (máximo 12 meses, ideal 6 meses);

- fornecer métricas dos diferentes processos de editoração;

- agilizar a publicação dos artigos por meio da modalidade avançada (ahead of print) ou publicação continuada tão logo os artigos estejam prontos.

Estas medidas se inserem no compromisso assumido pelo SciELO desde sua criação em 1996, as quais contribuem para o aumento sustentável de sua visibilidade de acordo com padrões internacionais de indexação, publicação e interoperabilidade.

Independente de estarem indexados nesta biblioteca eletrônica, entende-se que todos os periódicos da enfermagem devem adotá-las, de modo a adequarem-se às exigências da comunicação científica de qualidade.

A essas estratégias soma-se o fortalecimento de iniciativas e ações no campo da comunicação científica em enfermagem na Região das Américas como a iniciativa BVS Enfermagem, o Portal de Revista REV@ENF, o Fórum de Editores da ABEn e a Rede Iberoamericana de Editoração Científica em Enfermagem. ${ }^{4}$

0 processo de produção científica é deveras complexo, pois é eminentemente humano, traduzindo-se numa rede intrincada de sujeitos ou atores que em sua singularidade têm de dialogar com a comunidade cientifica, que ao mesmo tempo em que é impar mediada por suas crenças e cultura, também é plural, pois é direcionada a todos que dela podem ou não se benificiar. ${ }^{5}$

Neste contexto, a internacionalização e visibilidade da comunicação científica em enfermagem é um grande desafio para os editores dos periódicos científicos de enfermagem na medida em que se insere em quatro grandes dimensões quais sejam humana, científica, social e política.

\section{REFERÊNCIAS}

1. Backes DS, Backes MS, Lunardi VL, Erdmann AL, Buscher A. Internacionalização como desafio ao impacto da globalização: contribuições da enfermagem. Rev Esc Enferm USP. 2014;48(5):772-7.

2. Scientific Eletronic Library Online (ScieloBR). Critérios, política e procedimentos para a admissão e a permanência de periódicos científicos na Coleção SciELO Brasil. São Paulo; 2014.

3. Scochi CGS, Munari DB, Pedreira MLG, Padilha MI, Marziale MH. A importância da qualificação dos periódicos para o avanço da produção e visibilidade da pesquisa em enfermagem. Texto \& Contexto Enferm. 2012;21(2):251-3.

4. Lana FCF. Processo de comunicação científica em enfermagem. Rev Gaúcha Enferm. 2015;36(3):8-9.

5. Crossetti MGO. Panorama da publicação científica: desafios aos editores nacionais. Rev Gaúcha Enferm. 2014;35(4):8-9. 